\title{
Garlic reduces effect of Actinobacillus pleuropneumoniae infection in pigs
}

\author{
$\underline{\text { Mull }} \underline{M}$. * $^{*}$ \\ Beckerl, P., Van der Peet-Schwering', C. and N. Stockhofe-Zurwieden $^{2}$ \\ 'Wageningen UR Livestock Research, Lelystad, The Netherlands \\ ${ }^{2}$ Central Veterinary Institute, Lelystad, The Netherlands \\ * PO Box 65, $8200 \mathrm{AB}$, Lelystad, The Netherlands \\ e-mail: Monique.Mul@wur.nl; fax: +31320293591
}

\begin{abstract}
Lung diseases in pigs are among the most important health problem in pig husbandry, and generally treated with antimicrobials. To reduce the amount of antimicrobials used in pigs, we tested the preventive effects of freeze dried garlic added to feed on an infection with Actinobacilluspleuropneumoniae (APP).

Thirty male pigs of about seven weeks of age were aerosol challenged with APP serotype 2. Fifteen pigs received 5\% (w/w) garlic added to their diet (Garlic group), from two days prior to infection until four days after infection. The others received the a standard diet (Control group).

There was no difference in the number of pigs with symptoms of lung diseases. 48 hours after infection, the number of white blood cells had significantly increased in the Control group but not in the Garlic group. In the Control group a positive correlation ( $p<0.001$ ) was found between the occurrence of clinical respiratory disease signs and pathological findings. This correlation was not found in the Garlic group ( $p=0.15)$. We conclude that feeding high concentrations of freeze dried garlic does not prevent an APP infection, however, it affects the course and reduces the severity of an APP infection
\end{abstract}

\section{Introduction}

The development of antibiotic resistance possibly due to the use of antibiotics in animal production has resulted in a growing public concern (Rijsman et al., 2010). Organic farms aim to produce animal products without the help of antibiotics, mainly through preventive and stress reducing measures, but also by using alternative curative treatments. Lung diseases, endo- and ectoparasites and diarrhoea are the main health problems in Dutch organic pig herds. Actinobacilluspleuropneumoniae (APP) is a lung disease which is prevented by vaccination or treated with antibiotics (Van der Meulenet al., 2006). Dutch organic pig farmers are looking for alternatives to reduce the use of antibiotics and prevent APP. Garlic is a possible immunostimulant and has an anti-microbial activity (Sohnet al., 2009; Hariaiet al., 2010; Liv et al., 2010). Volatile sulphurous compounds are essentially responsible for the garlic smell of the exhaled air, and allyl methyl sulphide (AMS) is one of the most stable decomposition products of garlic in the body. AMS can exert antibacterial effects in the lungs (Hell and Kruse, 2007; Kyung and Lee, 2001). In vitro tests with AMS showed an antibacterial effect against APP serotype 9: it impaired the in vitro growth rate by $8 \%$ (unpublished data). The present study aims to test the preventive effect in vivo of freeze dried garlic added to feed on an infection with APP.

\section{Material and Methods}

Thirty male pigs of about seven weeks of age were aerosol challenged with APP serotype 2 (reference strain 1536) in a stainless steel incubator. Aerosols were introduced with an Aeroneb ${ }^{\mathrm{TM}}$ Pro micropump nebulizer (Aerogen Ltd., Galway, Ireland). $5 \mathrm{ml}$ of the inoculum containing 1×109cfu/ml was completely dispersed within 30 minutes. Fifteen pigs received a $5 \%(w / w)$ garlic constituent of Enteroguard ${ }^{T M}$ (Orffa Additives, The Netherlands) added to their diet (Garlic group), from two days prior to infection until four days after infection. The others received a standard diet (Control group). Body temperature, appetite, and behaviour of all pigs were monitored daily. White blood cells (WBC) were counted three days before the exposure and at day one and three after exposure. At four days after exposure the pigs were euthanized. Gross pathology findings were recorded, tissue samples were taken and lymph nodes were histologically and bacteriologically examined. AMS was measured in blood sampled from the pigs at the day just before the exposure and at day four after exposure.

The analysis of variance was applied to test the effects of the garlic diet on WBC count at days 1 and 2 after inoculation. Differences of lung weights between the two groups were analysed by using a two tailed Mann-Whitney $U$ test. 
Occurrence of pneumonia was compared between both groups by Fischer's exact test. For each treatment Spearman's rank correlation coefficient was used as a measure of association between the rankings of clinical sign severity and post mortem severity scores on the animals.

\section{Results}

Feed intake was temporarily reduced in the afternoon following the challenge with APP (Table 1). The AMS content in the garlic-fed group before challenge (i.e. 4 days after the 5\% garlic administration), was lower (324 \pm 128 nM) than at day 4 after challenge (i.e. after 9 days of administration (422 \pm 194 nM)). The differences between the average AMS content before and after challenge were not statistically significant. In the blood of the animals from the control group no AMS was detected above the minimum detection limit of $4 \mathrm{nM}$ (Table 1 ).

Table 1: Average feed intake and standard deviation and average AMS content in blood of the pigs and standard deviation in the garlic fed group and in the control group.

\begin{tabular}{lcccc}
\hline & \multicolumn{2}{c}{$\begin{array}{c}\text { Feed intake (g/meal } \\
\pm \text { st. dev.) }\end{array}$} & \multicolumn{2}{c}{$A M S$ ( $n M \pm$ st. dev.) } \\
\hline Study & $\begin{array}{c}\text { before } \\
\text { exposure }\end{array}$ & $\begin{array}{c}\text { after } \\
\text { exposure }\end{array}$ & $\begin{array}{c}\text { before } \\
\text { exposure }\end{array}$ & $\begin{array}{c}\text { after } \\
\text { exposure }\end{array}$ \\
\hline Garlic & $292 \pm 30$ & $263 \pm 79$ & $324 \pm 128$ & $422 \pm 194$ \\
\hline Control & $291 \pm 19$ & $279 \pm 58$ & $<4$ & $<4$ \\
\hline
\end{tabular}

In $35 \%$ of clinical recordings respiratory symptoms were observed in both groups, but no difference was seen between the two groups (Table 2). Increases in body temperature of $>39.5^{\circ} \mathrm{C}$ were seen in 3 out of 15 pigs of the garlic-fed group and in 8 out of 15 pigs from the control group. Also, a lower percentage of recordings with an elevated body temperature were observed in the garlic-fed group (8.3\% vs. 17.5\%). In both groups, a significant increase of WBC count was observed at one day post infection ( $p<0.05)$. However, at three days post infection, WBC count was still significantly elevated in the control group ( $p<0.05)$, but not in the garlic-fed group.

One pig of the control group died 24 hours after inoculation due to severe pleuropneumoniae. During gross pathology examination, seven pigs of the control group had pleuropneumonia, pneumonia and/or pleuritis. In the garlic-fed group, five pigs had a pleuropneumonia, pneumonia and/or pleuritis. In囚lammatory changes such as oedema or cell infiltrations can in囚uence the relative lung weight. The mean relative lung weight was increased in the control group compared to the garlic-fed group (control group: $1.21 \pm 0.15 \%$; garlic-fed group: $1.13 \pm 0.10 \%$ ), indicating a protective effect in the garlic-fed group, reducing in囚ammatory changes after infection ( $p=0.06$ ).

A positive association between the occurrence of clinical respiratory disease signs and pathological findings was seen in the control group ( $p<0.001$ ), but not in the garlic-fed group ( $p=0.15)$. It appeared that pigs from the garlic-fed group, which had shown clinical symptoms, had not necessarily developed pathological lesions.

Table 2: Summary of the results after challenge with Actinobacilluspleuropneumoniae serotype2

\begin{tabular}{c|cccc}
\hline study & $\begin{array}{c}\text { Respiratory } \\
\text { symptoms }\end{array}$ & $\begin{array}{c}\text { \% animals with elevated } \\
\text { body temperature }>39,5 \\
{ }^{\circ} \mathrm{C}\end{array}$ & $\begin{array}{c}\text { Lencocyte } \\
\text { index (\%) }\end{array}$ & $\begin{array}{c}\text { Mean relative lung weight } \\
\text { at day 4 post challenge } \\
\text { (\%) }\end{array}$ \\
\hline Garlic & $35 \%$ & 8.3 & 63 & $1.13 \pm 0.10$ \\
Control & $35 \%$ & 17.5 & 71 & $1.21 \pm 0.15$ \\
\hline
\end{tabular}

a Number of recordings with respiratory disease signs/total number of clinical recordings after challenge

b Percentage of recording of a WBC count $>20 \mathrm{G} / \mathrm{l}$ one and three days post infection

\section{Discussion}

The clinical and pathological changes induced were mild and comparable with most APP infections in pig farms. The effect of garlic on the clinical symptoms could not be shown in this study. However the lower lung weight in the garlic group compared to the control group and the lower WBC counts for two days in the garlic group compared to the control group suggest a reduced in囚ammatory response. The effects of garlic in this study were achieved with $5 \%$ of freeze dried 
garlic added to feed. In practice $1 \%$ is advised to be cost effective. Future studies are necessary to determine the dose effects relationship of garlic and prevention of the clinical signs of an APP infection.

\section{Conclusion}

It seems that feeding high concentrations of freeze dried garlic does not prevent an APP infection, however, it affects the course and reduces the severity of an APP infection.

\section{References}

HARJAI K., KUMAR R. AND SINGH S., 2010. Garlic blocks quorum sensing and attenuates the virulence of Pseudomonas aeruginosa. FEMS ImmunologyandMedicalMicrobiology, 58, 161-168.

HELL R. AND KRUSE C., 2007. Sulfur in biotic interactions of plants, In: Hawkesford M.J. and De Kok L.J. (Eds.) Sulfur in Plants - an Ecological Perspective. Springer Netherlands, pp. 197-224.

KYUNG K.H. AND LEE Y.C., 2001. Antimicrobial activities of sulfur compounds derived from S-alk/enlyl-L-cysteine sulfoxides in Allium and Brassica. Food Reviews International, 17, 183-198.

LIU S., SUN Y., LI W., YU H., LIX., LIU Z., ZENG J., ZHOU Y., CHEN C. AND JIA J., 2010. The antibacterial mode of action of allitridi for its potential use as a therapeutic agent against Helicobacter pylori infection. FEMS Microbiology Letters, 303, 183-189.

RIJSMAN V., MEVIUS D., NODELIJK G., SMITH H., MAASSEN K., BOERSMA W., KOENE M., BERGEVOET R., STOCKHOFE-ZURWIEDEN N., JANSMAN A., REBEL A., SMITS M., FELS B. VAN DER, NAPEL J. TEN, KIMMAN T., 2010. Banning antibiotics, reducing resistance, preventing and fighting infections. White paper on research enabling an 'antibiotic-free'animal husbandry. Edited by Kimman T., Smits B., Kemp B., Wever P. and Verheijden J. March 2010, $64 \mathrm{pp}$.

SOHN D.W., HAN C.H., JUNG Y.S., KIM S.I., KIM S.W. AND CHO Y.H., 2009. Anti-in囚ammatory and antimicrobial effects of garlic and synergistic effect between garlic and ciproßboxacin in a chronic bacterial prostatitis rat model. International Journal of Antimicrobial Agents, 34, 215-219.

VAN DER MEULEN J., VAN DER WERF J.T.N. AND KIILSTRA A., 2006. Questionnaire survey of disease prevalence and veterinary treatments in organic pig husbandry in the Netherlands. Veterinary Record, 159, $816-818$. 